\title{
El Arte Taíno
}

\author{
Taíno Art \\ DOI: https://doi.org/10.5377/koot.v0i11.10738 \\ URI: http://hdl.handle.net/11298/1194
}

Dr. Jaime Alberto López Nuila Abogado. Investigador Asociado UTEC

ORCID: 0000-0002-2217-4162

jaime.lopez@utec.edu.sv

\section{Resumen}

Fecha de aceptación: diciembre 2020

Este artículo describe de forma somera el quehacer social y cultural de los pueblos Taínos; sus características particulares muy propias, como lo fueron sobre todo el uso de aros de piedra para sus ofrendas religiosas, a su vez, nos muestra quehaceres de este pueblo como por ejemplo, su vocación para la agricultura mediante el uso de sistemas relativamente desarrollados que no impidieron su dependencia histórica de la caza y muy especialmente de la pesca. Las probadas experiencias de este pueblo para el uso de la yuca, de la cual ellos sacaban lo que llamaban Cazabi que es el mismo Casabe que hoy consume el pueblo dominicano. Ese cazabi era el pan de los indios Taínos, que luego de Colón se convierte en el pan de las Indias, porque a falta de trigo, importado de España, el colonizador europeo, conocedor acostumbrado al sabor de la yuca lo utiliza con mucha amplitud y con aceptación general. Las plantaciones de yuca eran los conocidos conucos para aquel pueblo originario.

Palabras clave: Arte taíno - Caribe (región). Caribe (región) - historia - vida social y costumbres. Arte taíno - República Dominicana. Cultura - República Dominicana. Caribe (región)- historia - aspectos socioeconómicos.

\begin{abstract}
This article briefly depicts the social and cultural works of the Taíno people: their particular characteristics, like the use they had of the Stone rings used during their religious offerings; at the same time, it shows other activities like their vocation towards agriculture through the use of relatively developed systems which did not hold them back from the historical dependency on hunting, and especially, on fishing. They proved to master the art of using yucca in different manners, like the extraction of what they called Cazabi-the same Casabe [or
\end{abstract}


cassava] that the Dominicans eat today. Cazabi was the equivalent of bread for the Taínos, and this later became the bread for the Indias after Columbus' arrival since no wheat was imported from Spain; the European settler, used to the taste of yucca, used it widely and it gained great acceptance from his people. Yucca plantations were known as conucos for the originary peoples.

Key words: Taino art - Caribbean (region). Caribbean (region) - history social life and customs. Taino art - Dominican Republic. Culture - Dominican Republic. Caribbean (region) - history - socioeconomic aspects.

\section{Introducción}

\section{La Sociedad Taína}

Las islas que forman parte de lo que geográficamente llamamos Antillas, en los años del descubrimiento de América por Cristóbal Colón estaban habitadas por pueblos originarios en su inicio, de la convergencia de los ríos Orinoco en Venezuela, y Zingú, Tapajos en lo que hoy llamamos Guyanas. Eran poblaciones originarias de la región nordeste de América del Sur y su vida estaba determinada esencialmente de su habilidad para conectarse mediante el uso de la canoa, para desplazarse entre aquellos grandes ríos continentales.

Aquella forma nómada de vida incluye en la época del Siglo XV y siguientes, su traslado entre las islas al ahora llamado Mar Caribe, y de aquella movilidad nace la población incontenible de aquel mundo insular. La población del caribe por aquellos pueblos de Sur américa fue paulatina, y comienza, parece, con los pueblos conocidos como los Siboneyes que se asientan en algunas partes de la Española y de Cuba. Ellos no conocen todavía la agricultura y sobreviven con base a la pesca y en menor medida de la caza de algunos animales propios del entorno, y habitaban sobre todo en pequeñas habitaciones construidas a la orilla de los ríos (Moya Pons, 1992, pp. 1-11).

Tiempo después se produce la migración de los pueblos que dependen del gran tronco Arauaco del nivel arqueológico llamado Igneri, y que pueblan las llamadas Antillas menores, incluyendo la Isla de Puerto Rico, y desplazando con el tiempo los pocos asentamientos Siboneyes que aún sobreviven, y cuya característica primera, como medida de desarrollo socio-económico es una muy avanzada práctica de la alfarería. Viene luego un período de expansión de la cultura Arauaca que conduce a la extinción total de los pueblos Siboneyes, expansión que unida al fenómeno de la sedentarización produce el aparecimiento de una cultura propia diferente, con valores culturales y 
míticoespirituales particulares, y que produce el nacimiento de lo que luego llamaron la Cultura Taína.

Hay, en la historia de los pueblos del mar caribe, una última etapa que tiene siempre como motor esencial un nuevo desplazamiento de las costas de Sur américa, siempre en canoas, de un pueblo diferente de los Siboneyes y Arauacos, los temidos Caribes, con características diferentes, que eran grandes navegantes, con gran experiencia en el uso del arco y la flecha, como medio de caza, y de defensa y ataque, comedores de carne humana según reconocidas fuentes y que no demoran mucho tiempo en asimilar lo que quedaba de los pueblos Igneris a quienes hacen desaparecer por completo, constituyendo las comunidades que habitan ese mundo insular para cuando se produce el descubrimiento.

Cuando Cristóbal Colón descubre América, las llamadas Antillas estaban ocupadas por esos pueblos guerreros llamados Caribes, que, en aquel contexto histórico, mantienen el asedio contra los pueblos Taínos, por lo que en aquella época de fin del Siglo XV es el desarrollo último de la cultura Taína que ahora nos ocupa, particularmente en cuanto a sus creencias religiosas. Aquel origen étnico del habitante de la isla Española - y en general de todos los pueblos insulares Caribeños - está fielmente acreditado en similitudes lingüísticas, en el uso de viviendas similares, en el consumo del tabaco, en el cultivo del maíz y la yuca, en la construcción y uso de canoas como medio de transporte interislas y hasta el continente más cercano y también en el uso de la hamaca como instrumento de descanso (Moya Pons, 1992, pp. 1-11). También mostraban los pueblos Taínos, - por otra parte - algunas características particulares muy propias, como lo fueron sobre todo el uso de aros de piedra para sus ofrendas religiosas. Pero para la posteridad, la cultura Taína dejo su vocación para la agricultura mediante el uso de sistemas relativamente desarrollados que no impidieron, su dependencia histórica de la caza y muy especialmente de la pesca. Dejaron los Taínos sus probadas experiencias para el uso de la yuca, de la cual ellos sacaban lo que llamaban CAZABI que es el mismo Casabe que hoy consume el pueblo dominicano. Ese cazabi era el pan de los indios Taínos, que luego de Colón se convierte en el pan de las Indias, porque a falta de trigo, importado de España, el colonizador europeo, conocedor acostumbrado al sabor de la yuca lo utiliza con mucha amplitud y con aceptación general. Las plantaciones de yuca eran los conocidos conucos para aquel pueblo originario.

Después de la yuca, el maíz, - que se consume tierno, crudo o asado, - junto con las batatas que consumían asadas y hervidas los Igneris, el maní acompañado de casabe, y las yahutias, formaban parte de la dieta vegetal del pueblo Taíno. 


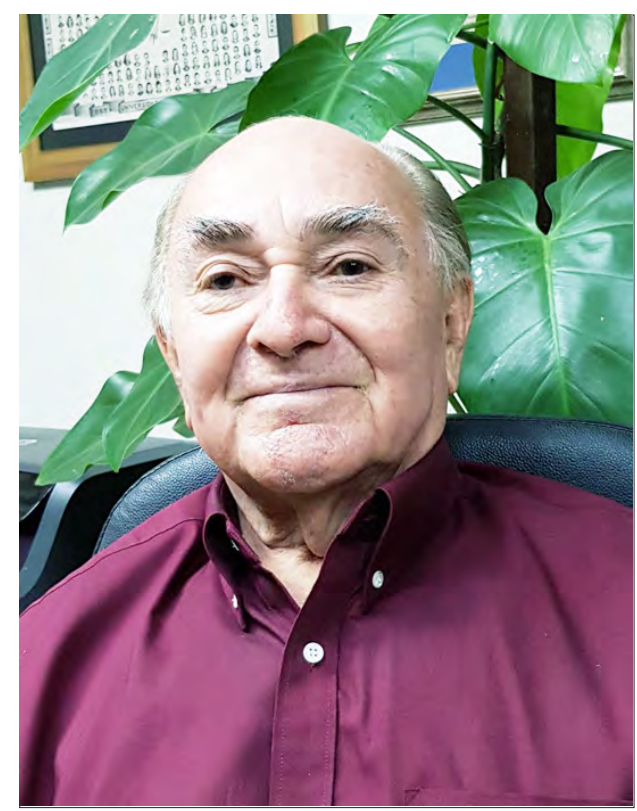

Dr. Jaime Albeto López Nuila

\section{El Arte Taíno}

Desarrollado sobre todo en la parte Este de la Isla Española - Santo Domingo está relacionado con la economía y la vida en sociedad de aquellas viejas culturas y que terminan por definir en gran parte la historia de la sociedad moderna, en este caso, de la sociedad de la República Dominicana de hoy. Estaba siempre esa vocación al arte, de la artesanía y de las muestras culturales de la sociedad TAINA, al servicio de sus creencias religiosas y mágicas.

Moya Pons, (1992), reconocido historiador y Antropólogo Dominicano, dice que aquella vocación artística Taína - Artesanía y Literatura- "eran en verdad súplicas y exposiciones constantes a los diferentes Dioses encarnados en variados elementos fundamentales en esta sociedad" y que además explicaban el origen, la vida, los problemas y en general el estilo de vida y las esperanzas de aquellos pueblos primitivos. Es de esas creencias míticas y mágico- religiosas, de las que se derivan las lluvias, el sol, el crecimiento de la yuca y hasta la fertilidad de las mujeres. De otro lado, esas creencias y aquellos elementos, a los que rinde tributo el Taíno, también responden en determinado momento, de las fuerzas que desencadena el huracán que trae muere y destrucción a la Isla. (pp. 1-11). 


\section{El Arte Religioso}

Frank Moya Pons, en su investigación histórica sobre el Arte Taíno, publicado en 1983 por el Banco Central de la República Dominicana, informa que los variados objetos de culto en la forma del arte Taíno, constituyen un rico ajuar ceremonial que se ha descubierto por investigadores antropólogos dominicanos, y está íntimamente ligado al panteón anímico del pueblo taíno. Dice Montás, Borrell y Moya Pons (1983), que: "estos objetos y piezas situados en su verdadero contexto cultural, identifican las representaciones de murciélagos y búhos con el espíritu de los muertos, pues aquellos son animales que habitan en cuevas y solo salen de noche. Las cuevas eran lugares sagrados para los indios, visitadas solo por los Chamanes (brujos) o behíques, porque en ellas -las cuevas- habitaban los espiritus de los difuntos".

Aquellas creencias, mágico-religiosas del pueblo Taíno incluye por ejemplo "rostros con grandes lágrimas brotando de los ojos" y que son en verdad auténtica representación de Dios, de la lluvia y también los llamados trigonolitos o piezas triangulares o de tres puntas, y que para la vida cotidiana del indio era la representación en abstracto de los montículos agrícolas, una forma efectiva del cultivo de la tierra, específicamente de la yuca, que ya conocemos, es un elemento básico en la dieta alimenticia del pueblo Taíno.

Debemos conocer entonces que el variado arte Taíno es una recopilación de las creencias mágico religiosas que regían la vida de aquel primitivo pueblo, y se acredita a Fray Ramón Pané - el primer etnólogo del nuevo mundo y acompañante de Colón en su segundo viaje a quien se le atribuye históricamente el mérito de interpretar el significado de las más conocidas manifestaciones de la cultura del pueblo originario en la isla Española, ya en la forma de sus creencias mítico-religiosas, y también sobre todo en el significado de sus diferentes vocaciones en artesanía y toda otra expresión como nación.

\section{Ceremonia De La Cohoba}

Bernardo Vega, intelectual dominicano, en la presentación del libro - "Arte Taíno" - 1983, Serigraf, Editado por el Banco Central Dominicano, - Pág. 4habla de la llamada Ceremonia de la Cohoba, en la que el dominicano calificado para ello - Shamanes o Behíques - entraban en contacto con los dioses.

Dice Bernardo Vega: "que el indio después de un largo ayuno purificador que lo reducía a un esqueleto andante, completaba la purificación limpiando su estómago con una espátula vómica introducida por su boca, sentado en un banquillo de madera o dúho, inhalaba un fuerte alucinógeno que tomaba desde 
un plato o bandeja de madera, colocado encima de un cemí, es decir de un idolo. El alucinógeno le permite comunicarse con el panteón de los dioses Tainos, quienes le auguraban el porvenir y le instruían acerca de cómo debía comportarse en el futuro. La espátula, el inhalador, el plato, el cemi y el duho son el ajuar del ritual, constituyen uno de los más ricos exponentes de la calidad artística neta tainos".

Esta ceremonia de la Cohoba que se ha detallado, completaba el ajuar ceremonial también enumerado, con unas maracas de madera y se indica que la posición del indio celebrante de la ceremonia, era con las piernas acuclilladas, con las manos en las rodillas, y su importancia cultural se destaca copiándola en ídolos y en los vasos efigies para indicar la participación en el ritual.

\section{EI Ajuar Personal Y Utilitario}

La Cohoba incluía adornos personales del indio celebrante que disponía de coronas y cinturones de huesos de pescado y piedra, así como collares y amuletos. Los amuletos eran destacadas esculturas en miniaturas llamadas "idolillos" que se colgaban en la frente y en el cuello. Las caretas llamadas también "Guaizas" eran sin duda verdaderas joyas de artesanía Taína, pero según parece no sobrevivieron a la destrucción de las Indias, lo que es sin duda, una pérdida irreparable para la cultura universal. También son parte del ajuar personal del indígena celebrante de la Cohoba, las llamadas orejeras, narigueras, adornos labiales y peinetas. Para cumplir su papel en la ceremonia el indio tatuaba su cuerpo con sellos o pintaderas de cerámica. Este es el personaje central de la Cohoba, caracterizado por todo aquel ajuar corporal, que se unía a elementos externos y al estado anímico del celebrante, que como sabemos era muy particular.

Había en la ceremonia los llamados objetos utilitarios que ellos confeccionaban con adornos, para vincularlos a propósitos rituales o funerarios señalando una siempre presente relación entre lo místico y lo material. Este es el papel de ollas, potizas y vasijas de barro. Esos vasos efigies son célebres en el arte del pueblo Taíno y su carácter es siempre de exponentes del más elevado valor porque comúnmente eran elaborados con forma humana y representativa, en otra reiteración elocuente de que el arte fue camino de expresión del espíritu y el sentimiento más íntimo del pueblo Taíno. Según Bartolomé de Las Casas (1987), habia también en el ajuar hachas impresionantes que por lo mismo son como una fotografia de la llama que prende en aquel pueblo, que un día De Las Casas llamaría una nación de "mansos y humildes". 


\section{El Arte Taíno en la Música}

Por otra parte, como representativo de los instrumentos musicales que acompañaban la ceremonia Taína, se cuentan los fotutos de lambi, las sartas de caracoles, las ocarinas y las vasijas, espátulas y sellos sonajeros, que muestran el carácter precursor de las prácticas contemporáneas de nuestros pueblos naturales.- Además del ingenio y la inteligencia propia del Taíno trasladados por supuesto a la cultura musical de nuestros pueblos indígenas de ahora, todas esas prácticas deslumbrantes para el ejercicio y la práctica de la música muestran un arte que se conserva en los pueblos de América. Hay que distinguir, no obstante, que además de la originalidad y preciosa autoría de aquellas manifestaciones culturales por medio de la música, el pueblo Taíno contenía en esa expresión artística musical, con aquel carácter totalmente original, también el propósito místico-religioso de la música que servía como telón de fondo a la comunicación espíritu-religioso del Shaman. Con las deidades o Dioses representativos de los diversos elementos naturales --- agua, sol, viento--, y todos los que, unidos íntima y profundamente a su estilo de vida, influían dramáticamente en la manera en que aquellos pueblos enfrentaban los elementos naturales, que la vida moderna, la llamada sociedad civilizada de ahora, enfrenta con el llamado cambio climático, y los efectos naturales que acarrea consigo.

Hay que resaltar que los objetos que integran el llamado ajuar utilitario de los Taínos, son una muestra elocuente de su reconocida laboriosidad, unida a un destacado sentido y amor por el arte, fabricando por ejemplo las hachas petaloides, el burén y los guayos para elaborar el casabe, los morteros y sus manos, las husos de hilar muestran su laboriosidad y sentido artístico, pero son igualmente, muestra de reconocible ingenio, al mezclar el propósito de llenar una práctica necesaria para llevar adelante su vida diaria, con un aporte de singular belleza y acabado.--

\section{La materia prima}

Es apreciable la preferencia del pueblo Taíno por el uso de la piedra para ordenar el curso de sus vidas. De piedra están elaborados collares, ídolos, hachas, pulidores, morteros, trigonolitos, aros y conos líticos de indescifrables y desconocidos usos.

También los llamados bastones ceremoniales, los buriles, las orejeras, las pesas de red, las cabezas de macorix, amuletos, husos de hilar y también famosos guayos. Pero no era la piedra la materia prima exclusiva que fundaba el vivir cotidiano del Taíno. También los elaboraban de madera, especialmente buscada y apreciada como el guayacán por su característico color oscuro y brillante. De 
este material están fabricados objetos que destacan por su singular belleza como ídolos diversos, bandejas, dúhos, maracas, remos, espátulas y cosas de madera oscura y brillante.

Asimismo, utilizaban la concha para elaborar fotutos, carátulas, idolillos y muchos adornos personales que usan para mostrar sobre todo al personaje principal del ceremonial religioso, pero también como artículos puramente personales. La natural habilidad y el ingenio Taíno reconoce otras materias primas para la comodidad de su hacer cotidiano, el hueso del manatí, que le sirve para fabricar espátulas vómicas, adornos labiales, inhaladores, cucharillas y amuletos, al tiempo que también se lucían con lindos collares elaborados con los dientes.

De algodón el Taíno elaboraba el conocido cemi, y de material de oro láminas martilladas, hechas de pepitas de oro decoradas. También era conocida en aquellos pueblos naturales la cestería, que incluía hamacas y redes que Bernardo Vega destaca que debió haber sido de la mayor calidad. La cerámica destaca por su belleza e incluye objetos tan preciados como vasijas, ollas, pintaderas, potizas, ocarinas, las burenas y las orejeras. Bernardo Vega, en su presentación de la obra "Arte Taíno" publicada por el Banco Central de la República Dominicana, destaca que la cerámica Taína esta detallada por lo que llama "simetría bilateral en los diseños o motivos" y que se caracterizan por ser incisos o punteados, geométricos y modelados, además del uso de una pasta de buena calidad.

--Las asas son usualmente utilizadas en las ollas para conseguir expresiones artísticas de una singular belleza. --

Dice Bernardo Vega, asimismo, que los Taínos practicaron un arte esencialmente escultórico por la evidente falta de pintura en la cerámica, habiendo manifestado sus virtudes para el dibujo en el arte rupestre, donde representa la fauna que puebla su hábitat, y también el variado ceremonial religioso que marca señaladamente su vida diaria, en motivos abstractos que se caracterizan por su reconocida simetría. Señala que las cuevas en República Dominicana contienen el tesoro más valioso del Caribe como muestra del citado arte rupestre.

Finalmente hay que señalar que el pueblo Taíno no conoce el hierro y el bronce, tampoco la técnica del molde y del torno alfarero, por lo que es la práctica del frotado con cáñamos, usando las bordas con filo de almejas y también para cortar piedra, madera, caracol o huesos. También aplicaban sus usos en buriles, pulidores, hachas de piedra y cualquier otro objeto de uso común en aquel ambiente en el que destaca el mar con todos sus infinitos recursos, que son fruto en la vida para el indígena. Es reconocible entonces que las manifestaciones 
artísticas que hemos detallado, se producen en un mundo primitivo, según el contexto histórico, en el que la nota característica es la ignorancia de las prácticas modernas que han conducido al desarrollo cultural de la sociedad de ahora, por lo que es vital reconocer el ingenio de aquel pueblo originario.

Cuando el almirante Cristóbal Colón, escribe sobre su hazaña del descubrimiento del llamado NUEVO MUNDO, en una de sus muchas comunicaciones o informes a la corona o simplemente como parte de lo que era su diario personal, el Almirante dice: "Esta-se refiere a la Isla La Española- es para desear, vista es para nunca olvidar". No hay que hacer ningún esfuerzo para entrar al corazón y la mente de aquel viejo y curtido navegante y hombre de mar para entender y atrapar ese sentimiento de admiración, de amor y de maravilla por aquél mundo nuevo y deslumbrante que amanece frente a su inteligencia y dentro de su corazón, del que destacan su increíble y soñada geografía y sobre todo, aquel pueblo único en su pureza espiritual y su inocencia humana. El Taíno es también, lo tenemos visto ahora una nación de especial ingenio y vitalidad espiritual.

\section{Referentes bibliográficos}

Bartolomé de Las Casas, F. (1987). Historia de Las Indias. República Dominicana: Sociedad Dominicana de Bibliófilos.

Montás, O., Borrell, P. J. y Moya Pons, F. (1983). Arte taíno. República Dominicana: Banco Central de la República Dominicana.

Moya Pons, F. (1992). Manual de historia dominicana. Barcelona, España: Industrias Gráficas. 
Pieza de Exposición

Museo Universitario de Antropología

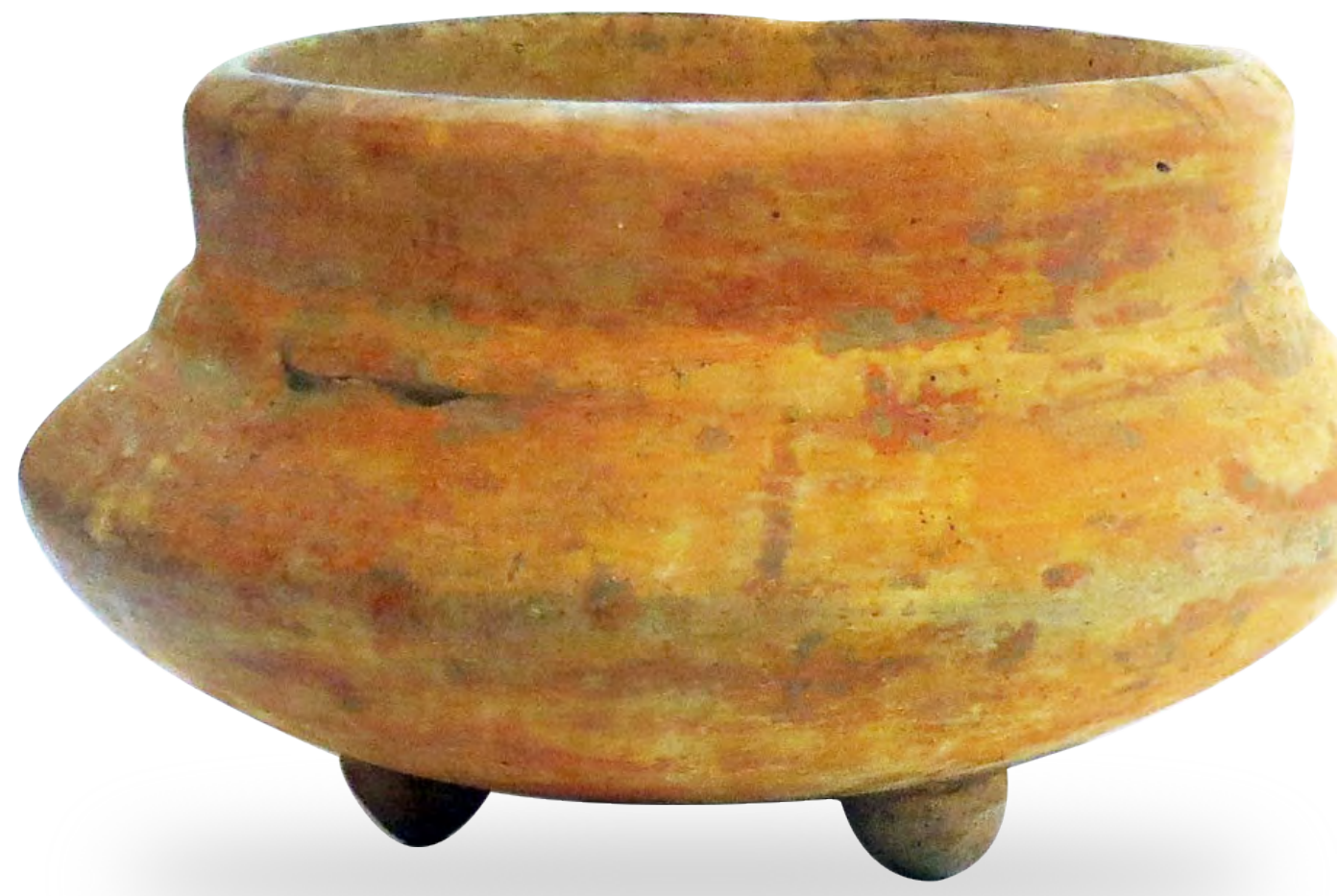

Cuenco

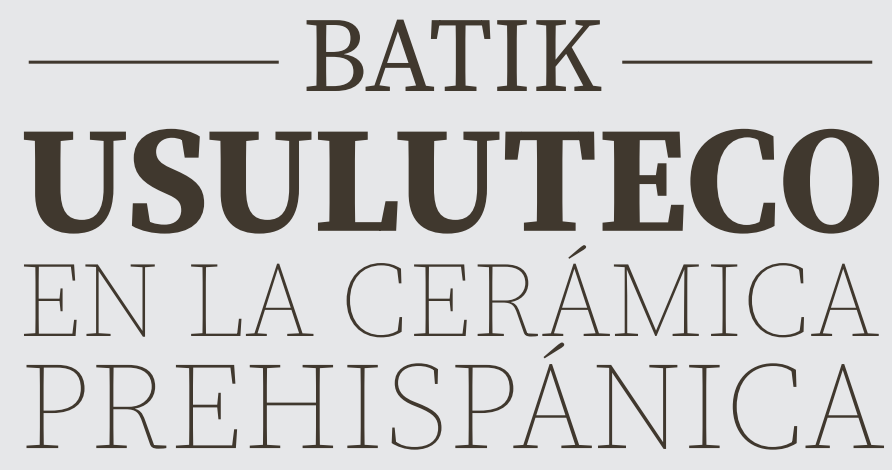

